\title{
Dystroglycan Expression in Hepatic Stellate Cells: Role in Liver Fibrosis
}

\author{
Pierre Bedossa, Sophie Ferlicot, Valérie Paradis, Delphine Dargère, Frank Bonvoust, \\ and Michel Vidaud \\ Service d'Anatomie Pathologique (PB, SF, VP), Hôpital de Bicêtre, Université Paris Sud, UPRESA CNRS-8O67 (PB, \\ VP, DD, FB), Faculté des Sciences Pharmaceutiques, Université Paris VI, and JE DRED 351 (MV), Laboratoire de \\ Génétique Moléculaire, Faculté de Pharmacie, Paris, France
}

\begin{abstract}
SUMMARY: Dystroglycan is a membrane component of the dystrophin-glycoprotein transmembrane complex. Its expression is required for the spatial organization of laminin on the cell surface and for basement membrane assembly. In view of the constitution of a perisinusoidal basement membrane during liver fibrosis, we studied dystroglycan expression in liver fibrosis. Dystroglycan mRNA and protein expression were investigated by immunofluorescence, Western blot, and quantitative RT-PCR (TaqMan) in normal human and rat liver and in isolated rat hepatic stellate cells. On Western blot, a 43-kd band corresponding to $\beta$-dystroglycan was observed in protein extracted from normal and fibrotic human and rat livers. The specific 43-kd protein was also detected in lysates from rat hepatic stellate cells but not from hepatocytes. By immunofluorescence, patchy deposits of $\beta$-dystroglycan were detected on membrane of hepatic stellate cells in culture. On Western blot and quantitative RT-PCR, an up-regulation of $\beta$-dystroglycan was shown during spontaneous activation of hepatic stellate cells in culture. Direct evidence for the role of dystroglycan in laminin-hepatic stellate cell interaction was shown because specific antibody directed against $\alpha$-dystroglycan inhibited partially hepatic stellate cell adhesion on laminin-coated plates. This mechanism was calcium dependent because EDTA inhibited cell/laminin adhesion, an effect reversed by addition of $\mathrm{Ca}^{2+}$. This study shows that dystroglycan is expressed on the membrane of hepatic stellate cells and is up-regulated during liver fibrosis. Dystroglycan interaction with laminin should be implicated in the concentration of pericellular laminin and in the constitution of a perisinusoidal basement membrane during liver fibrosis. (Lab Invest 2002, 82:1053-1061).
\end{abstract}

$D$ ystroglycan (DG) is a recently characterized transmembrane protein that plays a critical role in organizing extracellular matrix proteins on the cell surface (Hemler, 1999; Henry and Campbell, 1999). Originally isolated in skeletal muscle membrane as part of a protein complex called the "dystrophinglycoprotein complex," DG is expressed in a variety of cell types, indicating that its function is not restricted to muscle (Durbeej and Campbell, 1999; Durbeej et al, 1998b; Raats et al, 2000). It is encoded by a single messenger RNA that, by post-translation processing, forms the extracellular highly glycosylated $\alpha$-DG subunit and the smaller transmembrane $\beta$-subunit. These two subunits are noncovalently but tightly associated (Durbeej et al, 1998a). In muscle, $\alpha$-DG binds to extracellular matrix proteins containing laminin-type $G$ domains (laminin-1 and -2 , agrin, perlecan), whereas the $\beta$-subunit binds through its cytoplasmic tail carboxyl terminal portion to intracellular dystrophin and

\section{DOI: 10.1097/01.LAB.0000024429.73158.DE}

Received April 15, 2002.

This study was supported by grants from Association pour la Recherche contre le cancer and Fond de Recherche de la Sociéte Nationale Française de Gastroentérologie.

Address reprint requests to: $D r$. P. Bedossa, Service d'Anatomie Pathologique, Hôpital de Bicêtre, 78, rue du général Leclerc, 94275- Le Kremlin-Bicêtre Cedex, France. E-mail: pbedossa@teaser.fr dystrophin-related proteins (Bowe et al, 2000; Hohenester et al, 1999; Huang et al, 2000; Saito et al, 1999; Talts et al, 1999; Tisi et al, 2000). Therefore, DG is believed to form an important link between the cytoskeleton and the extracellular matrix.

A dynamic role for $D G$ in basement membrane formation has been recently demonstrated by genetic experimental evidence. In DG-null embryoid bodies, there was complete disruption of the basement membrane; and in embryonic stem cells, evidence showed that DG was needed to promote the assembly of a laminin matrix (Henry and Campbell, 1998). From these studies, it was suggested that DG is necessary for the formation of a basement membrane, fulfilling its role by nucleating the assembly of a laminin matrix on the cell surface.

Capillarization of the sinusoid is one hallmark of liver cirrhosis (Schaffner and Popper, 1963). Although the basement membrane is not detected at the ultrastructural level in the perisinusoidal space of normal liver, deposition of a continuous basement membrane along the perisinusoidal space is a characteristic feature of "capillarized" sinusoid in cirrhosis (BioulacSage et al, 1988). The mechanism of this de novo basement membrane deposition is still unknown. Because an increase in the production of basement membrane components including laminin-2 is observed in this condition, we hypothesized that DG might also be involved in this process (Lietard et al, 
1998). In the present study, we show that DG is expressed in the liver and that hepatic stellate cells (HSC) are the major cellular sources of DG production. Furthermore, up-regulation is observed both during stellate cell activation and in models of rat liver fibrosis. Finally, experimental evidence is provided showing a direct interaction between HSC and laminin through transmembrane DG.

\section{Results}

\section{DG Is Expressed in Rat and Human Livers}

To estimate whether DG is expressed in the liver, we conducted Western blotting experiments on protein extracted from human and rat normal livers using anti- $\beta$-DG and anti- $\alpha$-DG antibodies. With 43DAG, an antibody recognizing an epitope shared by human and rat $\beta$-DG, a specific 43-kd band was observed both in protein extracts from rat skeletal muscle, used as a positive control, and in rat and human livers (Fig. 1A). An additional 27-kd band was also observed in extracts from rat tissues (skeletal muscle and liver). As reported previously, this band corresponded presumably to a breakdown product containing the C-terminus of $\beta$-DG (Yamada et al, 1996). With IIH6 antibody, a specific antibody developed against the extracellular $\alpha$-DG; a specific broad band at approximately $160 \mathrm{kd}$, with a slight difference in molecular weight according to samples, was also detected in skeletal muscle and in whole human and rat liver extracts (Fig. 1B). These differences in molecular weights were related to variations in glycosylation of the extracellular $\alpha$-DG (Moukhles et al, 2000).

To assess the level of DG mRNA expression in the liver, mRNA was quantified by real-time quantitative RT-PCR. DG mRNA was detected at a low level in normal human and rat liver. In normal rat liver, DG mRNA was 5-fold lower than in skeletal muscle used as positive control. DG mRNA was also detected in heart, lung, and kidney. Relative mRNA levels in different rat organs are shown in Figure 1C.

\section{DG Is Expressed by HSC}

Because HSC is a potent candidate for DG expression, we studied, by Western blot, the expression of both the $\alpha$-DG and $\beta$-DG protein component in primary cultures of rat HSC after 4 days in culture on plastic. Using anti- $\beta$-DG antibody, the specific $43-\mathrm{kd}$ band was detected in protein extract of HSC but not in extracts from primary hepatocytes (Fig. 2A). Similar results were observed with $\mathrm{IIH} 6$ antibody, a specific antibody developed against the extracellular $\alpha$-DG (data not shown). DG expression by HSC was also supported by immunofluorescence of primary HSC 4 days after isolation. $\beta$-DG immunostaining appeared
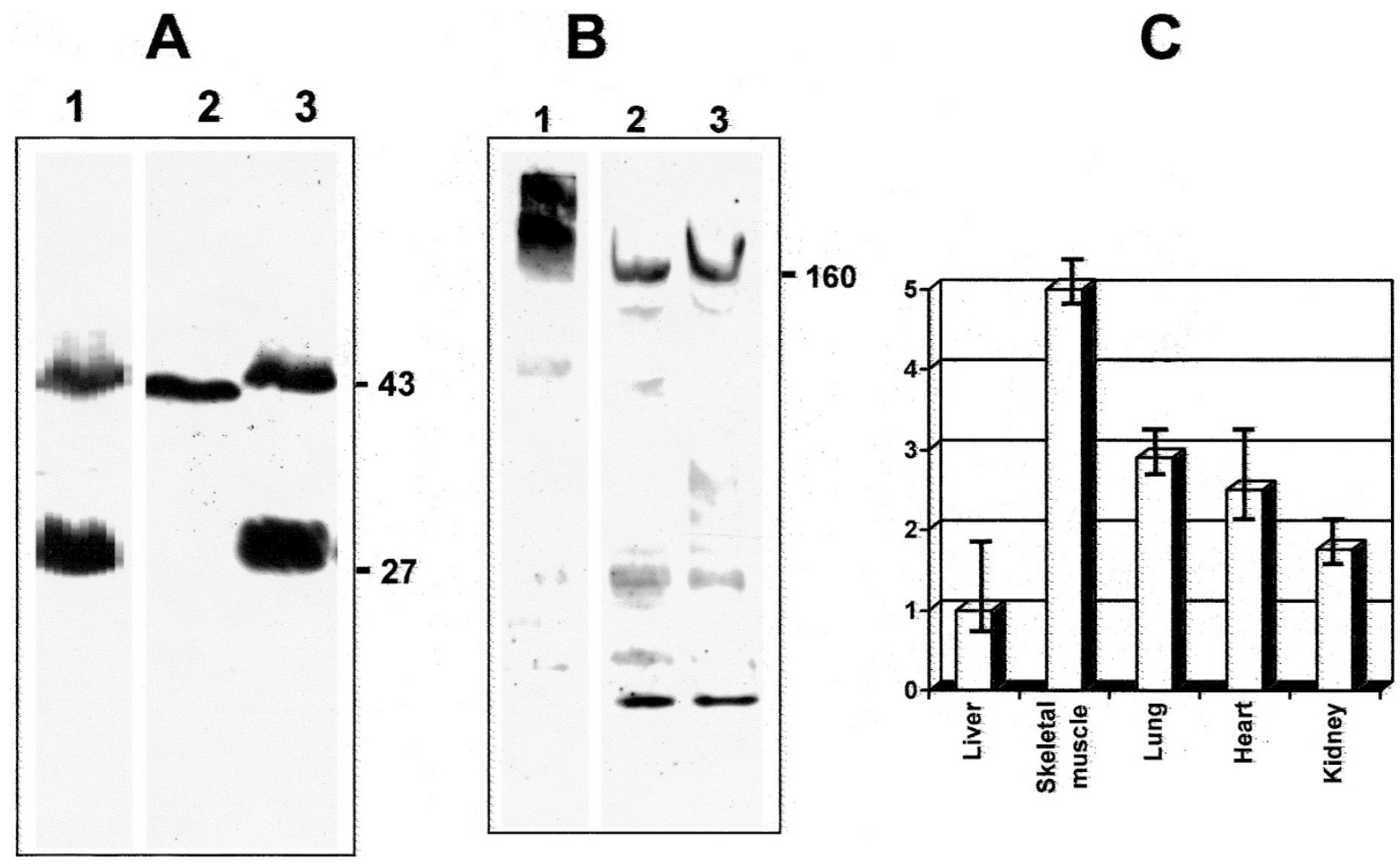

Figure 1.

Dystroglycan (DG) expression in rat and human livers. A and B, Homogenates from rat skeletal muscle (lane 1), normal human liver (lane 2), and normal rat liver (lane 3) were analyzed by Western blot against anti- $\beta$-DG antibody 43DAG (A) or anti- $\alpha$-DG antibody IIH6 (B). A specific 43-kd band was consistently observed with anti- $\beta$-DG antibody with an additional 27-kd band in rat tissues (lanes 1 and 3 ) that correspond presumably to proteolytic fragments of $\beta$-DG. With anti- $\alpha$-DG antibody, a major 160-kd band is observed. C, mRNA was extracted from liver, skeletal muscle, lung, kidney, and heart of normal Sprague-Dawley rats. mRNA DG was quantified using real time RT-PCR. The mRNA level of DG in the liver is defined as 1 unit of mRNA quantification. Results are expressed as mean value of three independent experiments $\pm \mathrm{SD}$. 
A

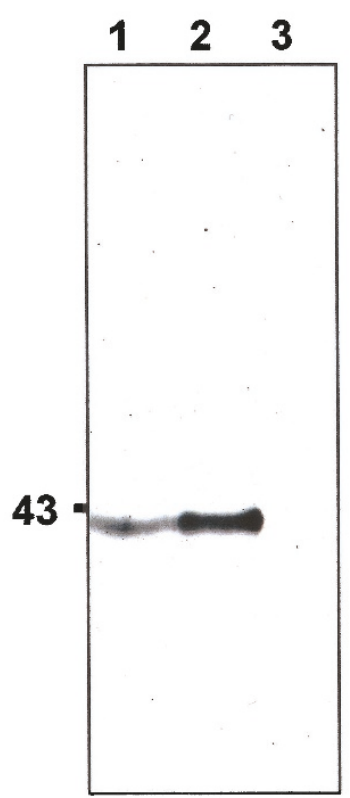

B

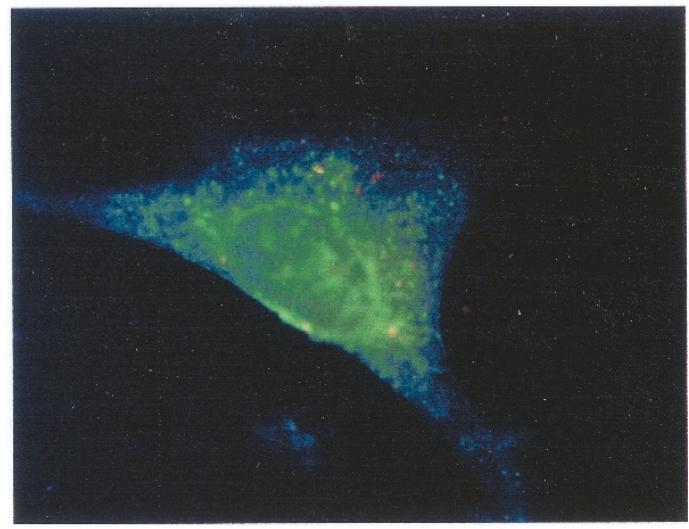

Figure 2.

DG is produced by hepatic stellate cells (HSC). A, Tissue or cell lysates from rat skeletal muscle (lane 1), rat HSC lysate after 4 days in culture (lane 2), and primary rat hepatocytes (lane 3) were analyzed by Western blot using anti- $\beta$-DG antibody. B, Immunofluorescence of $\beta$-DG in primary HSC. After isolation, cells were plated on coverslips, cultured for 4 days, and immunostained using anti- $\beta-D G$ antibody as described in "Materials and Methods." Patchy staining mainly located on the cell membrane is clearly visible.

as diffuse plaques located mainly on the cell membrane (Fig. 2B). Intracellular cytoplasmic staining was also detected, which probably corresponded to intracellular synthesis and recycling of the receptor. No staining was observed when indirect immunofluorescence was performed after omitting the primary antibody or with an irrelevant antibody.

\section{DG Is Overexpressed During Liver Fibrosis}

Because of the possible role of DG in basement membrane deposition during liver fibrosis, we compared the level of expression of DG in two rat models of liver fibrosis. In both chronic $\mathrm{CCl} 4$ intoxication and the bile duct-ligated model, septal fibrosis was present as shown on standard stained sections (Fig. $3 A)$.

In the model of chronic CCl4-induced fibrosis and in comparison to the control group, a 1.6-fold increase of DG mRNA expression was observed $(p<0.05)$. In parallel, collagen $\alpha \mathrm{l}(1)$ mRNA showed a mean 3.8-fold increase. In the bile duct-ligated model of fibrosis, a mean 3.2-fold increase in DG mRNA was observed in comparison to the sham-operated group ( $p<0.01)$. In parallel, collagen $\alpha \mathrm{l}(1)$ mRNA was increased 8.7-fold $(p<0.001)$. Results are illustrated in Figure 3B.

Because culture of primary HSC on plastic for several days reproduces the phenotypic modifications of HSC observed during liver fibrogenesis, we compared, by Western blot, $\beta$-DG expression in lysate of quiescent HSC obtained shortly after isolation with fully activated HSC after 7 days of culture. A strong up-regulation of the specific 43-kd band was observed (Fig. 3C).

This result was confirmed by immunohistochemistry of cirrhotic human liver. Using anti- $\alpha-D G$ antibody, staining of perisinusoidal cells was observed in cirrhotic human liver (Fig. 4). No staining was observed when primary antibody was omitted.

\section{DG Is Involved in Laminin-HSC Adhesion}

To assess the role of DG in the HSC-laminin interaction, HSC in their fully activated phenotype after 7 days in culture were plated onto laminin-coated dishes. After 2 hours, most HSC adhered and spread onto the laminin substrate (Fig. 5A). When cells were plated on the same substrate in the presence of $1 \mathrm{IH} 6$, a blocking antibody specific to the C-terminal extremity of the $\alpha$-DG, cells did not spread, but became rounded or aggregate in small clusters (Fig. 5B). Such an effect was not observed when nonspecific mouse IgM was used instead of IIH6 (Fig. 5C). IIH6 did not interfere with $\mathrm{HSC}$ adherence on plastic. This strongly suggests that $\alpha$-DG is involved in the laminin-cell interaction.

Because the laminin-DG interaction mechanism is known to be strongly $\mathrm{Ca}^{2+}$ dependent, we assessed cell adhesion on the laminin substrate in the presence of EDTA, a calcium chelator. Under this condition, 
A
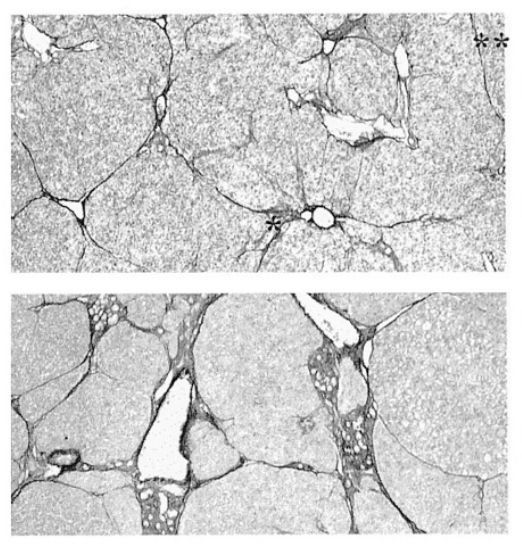

B

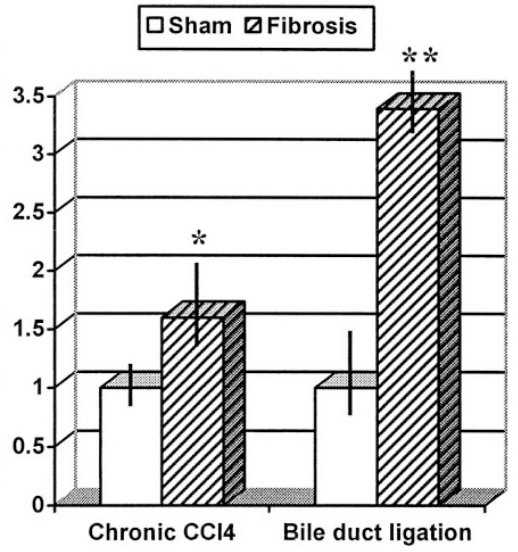

C

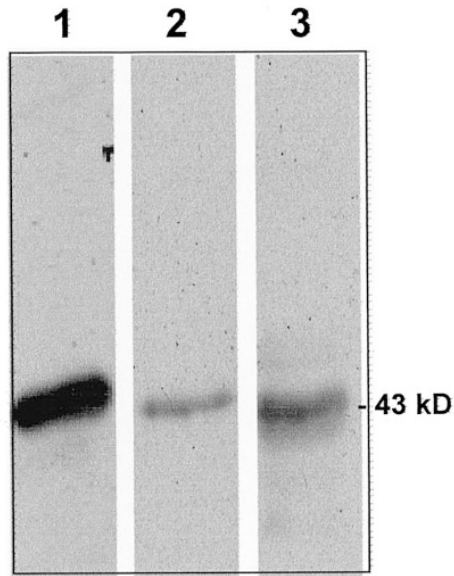

Figure 3.

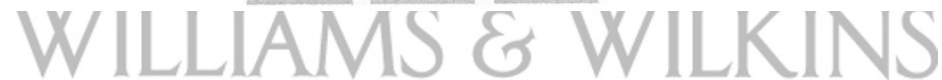

Up-regulation of DG during liver fibrosis and HSC activation. A, On Sirius red staining, septal fibrosis is obvious both after chronic CCI4 treatment (upper pane/) and after bile duct ligation (lower pane). B, Quantitative DG mRNA levels in sham (white bar) and fibrotic livers (hatched bar) in the two models of liver fibrosis (mean value of five animals $\pm \mathrm{SD}$ ). mRNA was extracted from livers and quantified using real time RT-PCR. The mean mRNA level of DG in the sham livers is defined as 1 unit of mRNA. ( ${ }^{*}=p<0.05,{ }^{* \star}=p<0.01$ by comparison to the sham group). C, Western blot of lysates from rat skeletal muscle (lane 1), quiescent HSC at 1 day after isolation (lane 2), and HSC in their fully activated phenotype at 7 days after isolation (lane 3 ) using anti- $\beta$-DG antibody.

most cells became rounded and did not adhere to laminin (Fig. 5D). The deleterious effect of EDTA was reversed when $\mathrm{Ca}^{2+}$ was added to the culture medium (Fig. 5E).

The number of adhesive cells under these different conditions was assessed using the lactate dehydrogenase assay. A $44 \pm 5 \%$ decrease in adhesive cells was observed in the presence of $\mathrm{IH} 6(p<0.01)$. Addition of both $\mathrm{IIH} 6$ and $\mathrm{Ha} 2 / 5$, a rat $\beta 1$ chain antibody, induced a $85 \pm 7 \%$ decrease in the number of adhesive cells, whereas control, nonspecific mouse lgM did not induce a significant decrease of cell adhesion (7 $\pm 4 \%$ ). Furthermore, adding EDTA to the cell medium induced a 93 $\pm 2 \%$ decrease in adhesive cells on a laminin support $(p$ $<0.0001$ ), which was totally reversed by adding $\mathrm{Ca}^{2+}$ to the culture medium (Fig. 5F).

\section{Discussion}

Basement membranes are highly specialized extracellular matrices largely composed of ubiquitous glyco- proteins including collagen IV, laminin, perlecan, and nidogen/entactin (Colognato and Yurchenco, 2000; Erickson and Couchman, 2000; Tunggal et al, 2000). At the ultrastructural level, the basement membrane appears as a sheet-like multilayered structure at the interface between epithelial and mesenchymal cells. The perisinusoidal space of the normal liver does not contain any organized basement membrane, although major constituents of the extracellular matrix components can be detected (Clement et al, 1985). In contrast, one of the characteristic morphologic patterns observed during liver fibrosis and cirrhosis is "capillarization" of the liver sinusoid. In this condition, a well organized basement membrane appears in the perisinusoidal space when viewed at the ultrastructural level (Bioulac-Sage et al, 1988). Because it has recently been shown that DG plays a fundamental role in early basement membrane assembly by facilitating the polymerization of laminins at the cell surface, we hypothesized that DG could also be implicated in basement 


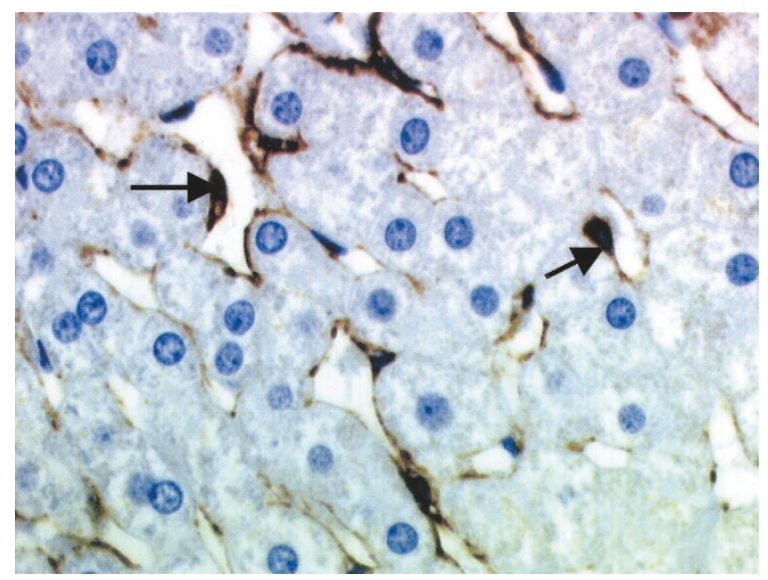

Figure 4.

$\alpha$-DG immunostaining in a cirrhotic human liver. Staining of perisinusoidal cells with long cell processes are observed along the sinusoid wall.

membrane formation in the Disse's space during fibrogenesis (Henry and Campbell, 1998).

Also initially described at the skeletal muscle membrane, other mesenchymal and epithelial tissues constitutively express DG, according to several reports (Durbeej and Campbell, 1999; Durbeej et al, 1998b; Raats et al, 2000). Indeed, we detected DG both at the protein and mRNA level not only in skeletal muscle but also, at a lower level, in several normal tissues including the liver. HSC are key cells in the process of liver fibrosis. During this process, HSC transform from quiescent lipid-storing round cells into pseudomyofibroblasts with acquisition of several new functions including production of major extracellular matrix components, motility, contraction, and multiplication (Eng and Friedman, 2000). The role of HSC in DG production was confirmed after cell isolation. Although no signal was detected on Western blot of hepatocyte lysate, a specific 43-kd band was detected with anti$\beta D G$ antibody and a specific band around $160 \mathrm{kd}$ was observed using anti- $\alpha$-DG antibody in HSC lysate. Furthermore, immunofluorescence confirmed the presence of $D G$ as patchy staining on the cell membrane of cultured HSC. Such a patchy membranous staining pattern has already been demonstrated in other cell types such as Purkinje cells, Schwann cells, and retina cells and has been considered to represent clustering of DG molecules (Campanelli et al, 1994; Cohen et al, 1997). The HSC are normally considered to be mesenchymally derived. Recent works have demonstrated that HSC not only express smooth muscle markers but also the glial fibrillary acidic protein, the neural protein, nestin, and the prion protein (Niki et al, 1999). These data have stimulated debate over whether HSC may be derived from the neural cells. Our demonstration of DG, a characteristic marker of both the central and peripheral nervous system, strengthen this hypothesis.

Our study shows that DG is constitutively expressed in the normal liver but at a low level. Because, in this condition, there is no basement membrane formation along the perisinusoidal space of the liver, we hypoth-
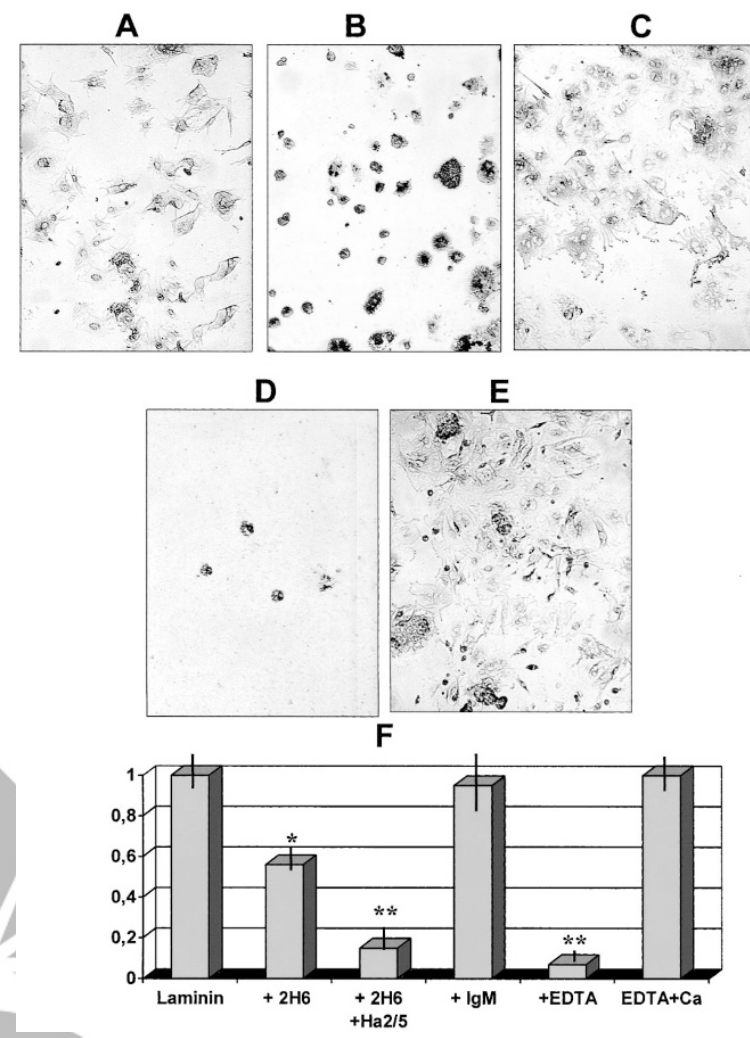

Figure 5.

Adhesion of HSC to laminin is inhibited by anti- $\alpha-D G$ antibody. A to E, HSC in their activated phenotype were seeded on laminin-coated dishes in the absence (A) or in the presence of anti- $\alpha$-DG (IIH6) at a 1:10 dilution (B), the presence of control $\operatorname{lgM}(\mathrm{C}), 5 \mathrm{~mm}$ EDTA (D), or with EDTA and $\mathrm{Ca}^{2+}$ (E). Photos were taken after 2 hours of incubation at $37^{\circ} \mathrm{C}$. F, Quantification of cell adhesion on laminin alone or in the presence of IIH6, IIH6 and $\mathrm{Ha} 2 / 5$ (an anti-Beta1 integrin), control IgM, 5 mMEDTA, or 5 mM EDTA with $\mathrm{Ca}^{2+}$ as determined by the lactate dehydrogenase activity released in the culture medium. Experiments were done in duplicate and repeated 2 times. Results are mean \pm SD. Values from laminin + IIH6, laminin + IIH6 and Ha2/5, or laminin + EDTA are significantly less than laminin alone or laminin + IgM or laminin + EDTA and $\mathrm{Ca}\left({ }^{\star}=p<0.01,{ }^{* \star} p<0.001\right.$ by comparison to the laminin alone group).

esized that this extremely low level of DG expression was inefficient to concentrate laminin molecules aggregation and that up-regulation of DG could occur during liver fibrogenesis, allowing perisinusoidal basement membrane organization. In accordance with this hypothesis, we observed up-regulation of DG mRNA expression in two different models of liver fibrosis. Furthermore, Western blot showed up-regulation of DG during spontaneous HSC activation, a model reproducing phenotypic modifications observed during liver fibrogenesis. Therefore, up-regulation of DG during liver fibrosis should be involved in liver sinusoid capillarization.

The closely related laminin-1 and laminin-2 isoforms are cross-shaped molecules with a tandem of five laminin G-like modules at the distal $\mathrm{COOH}$-terminal end of the long arm but with distinct differences in the precise location of these sites (Andac et al, 1999). Laminin-2 and, more recently, laminin-1 have been detected in the perisinusoidal space of the liver during the fibrogenesis process, and HSC have been shown 
to be responsible for their production (Lietard et al, 1998). In the present work, we show that, in HSC, $\alpha$-DG is a key molecule in laminin-HSC interaction because antibody IIH6, a blocking antibody that binds to $\alpha$-DG, partly and specifically inhibits HSC adhesion on the laminin substrate, whereas nonimmune lg does not. These data strongly reinforce the functional role of $D G$ at the cell surface. A constant feature is the strict calcium dependence of the laminin- $\alpha$-DG interaction (lbraghimov-Beskrovnaya et al, 1992; Rambukkana et al, 1998; Shimizu et al, 1999). We also show in these experiments that $\mathrm{Ca}^{2+}$ chelation by EDTA inhibits the laminin- $\alpha$-DG interaction in HSC, an effect reversed by further addition of $\mathrm{Ca}^{2+}$. Taken together, these results suggest that during liver fibrogenesis, up-regulation of DG in HSC may facilitate the contact between laminin and the cell surface through a $\mathrm{Ca}^{2+}$-dependent mechanism, perhaps allowing the organization of the threedimensional laminar structure of basement membrane in the perisinusoidal space of the liver.

However, membrane receptors other than $\alpha$-DG (such as integrins, a family of cell surface receptors) are involved in contact between cells and extracellular matrix. Previous reports have shown that HSC express several integrins including $\alpha 1 \beta 1, \alpha 2 \beta 1, \alpha 8 \beta 1$, $\alpha_{\mathrm{v} \beta} 1$, and $\alpha 6 \beta 4$, a group of heterodimers specifically involved in adhesion on laminin or fibronectin (Carloni et al, 1996; DiPersio et al, 1997; Iwamoto et al, 1998; Levine et al, 2000). Furthermore, these molecules are up-regulated during activation of HSC and in an experimental model of liver fibrosis (Levine et al, 2000). Because we observed that anti- $\alpha$ DG only partially inhibit laminin/HSC interaction and that adjunction of anti- $\beta 1$ antibody increased HSC detachment on laminin substrate, both $\alpha$-DG and integrins should be coordinately involved in basement membrane formation and laminin interaction.

The role of DG in interactions between cell and extracellular matrix has been demonstrated and, according to the present study, also occurs in the liver. Although DG might be implicated in extracellular matrix organization of the perisinusoidal space, its functional role is under investigation. Several lines of evidence suggest that DG is part of an intracellular membrane-anchored signal transduction complex that interacts with the SH3-domain of Grb-2. Grb-2 is an adaptor protein that helps to initiate the Ras-MAP kinase signal transduction cascade and is involved in controlling cytoskeletal organization (Colognato et al, 1999; Russo et al, 2000). Whether the DG complex is also involved in the structural reorganization of the cytoskeleton during HSC activation remains to be studied.

\section{Materials and Methods}

\section{Source of Materials}

Antibodies. Anti- $\beta$-DG antibody (clone 43DAG1/ 8D5) was purchased from Novocastra (Newcastle, United Kingdom). 43DAG1/8D5 is a mouse IgG monoclonal antibody directed against a synthetic peptide composed of 15 amino acids of the extreme C-terminus of the human DG complex.

Anti- $\alpha$-DG (clone IIH6) is a monoclonal IgM antibody directed against the extracellular $\alpha$-DG (kindly provided by K. Campbell, Howard Hughes Medical Institute, University of lowa, College of Medicine) (Ervasti and Campbell, 1993). Anti-rat $\beta 1$ chain antibody (clone $\mathrm{Ha} 2 / 5)$ was purchased from Becton Dickinson Transduction Laboratories (Le Pont de Claix, France).

Liver Biopsies and Tissue Samples. Normal livers ( $n$ $=5$ ) came from partial hepatectomy performed for size matching before transplantation. Cirrhotic livers ( $n$ $=2$ ) came from explanted livers with hepatitis C. For normal rat liver, we removed heart, kidney, lung, and skeletal muscle from three adult Sprague-Dawley rats. Tissues were snap-frozen in liquid nitrogen and stored at $-80^{\circ} \mathrm{C}$ until use. All experiments were performed according to procedures approved by the ethical committee, and informed consent was obtained from each patient.

\section{Immunofluorescence and Immunohistochemistry}

For immunofluorescence, primary HSC were fixed in alcohol/methanol (v/v) for 10 minutes at $4^{\circ} \mathrm{C}$. Samples were next washed two times in PBS for 5 minutes, then incubated with 43DAG antibody for 1 hour at a 1:100 dilution. After two PBS washes, samples were incubated with a fluoresceinated anti-mouse IgG (Sigma, Saint-Quentin Fallavier, France) for 1 hour at a 1:100 dilution. Slides were counterstained with Evans blue and viewed under a UV light microscope. For negative controls, cells or sections were incubated with normal serum or nonimmune $\mathrm{lg}$ instead of the primary antibödy.

The immunohistochemical procedure was performed on frozen sections of liver with the avidinbiotin-peroxidase method. Anti- $\alpha$-DG (clone IIH6) was used at a 1:100 dilution. We used normal sheep or rabbit serum or $\mathrm{PBS}$ as negative controls.

\section{HSC and Hepatocyte Isolation}

HSC were isolated from normal male Sprague-Dawley rats according to previously published protocols (Friedman and Roll, 1987). Briefly, the liver was dispersed by perfusion with pronase and collagenase. The resulting nonparenchymal cell suspension was filtered through a nylon membrane and washed three times in GBSS buffer containing $\mathrm{Ca}^{2+}$ (1.6 mM), $\mathrm{Mg}^{2+}$ (1.2 $\mathrm{mm})$, and DNAse, and then centrifuged through two successive Nycodenz gradients (Sigma), 15 and $10 \%$, respectively. After each gradient, HSC were recovered from the interface between Nycodenz and medium containing $0.3 \%$ BSA, washed in DMEM, and plated on uncoated tissue plastic at a density of $130 \times$ $10^{3}$ cells $/ \mathrm{cm}^{2}$ in DMEM supplemented with $10 \%$ each of calf and horse serum, $2 \mathrm{~mm}$ L-glutamine, $10 \mathrm{~mm}$ HEPES buffer, and $10000 \mathrm{Ul} / \mathrm{ml}$ penicillin $/ 10000 \mu \mathrm{g} / \mathrm{ml}$ streptomycin. Cultures were incubated at $37^{\circ} \mathrm{C}$ in a humidified atmosphere containing $95 \% \mathrm{O}_{2}, 5 \% \mathrm{CO}_{2}$, and the medium was changed every day. Viability was 
assessed by trypan blue exclusion test. Purity was more than $95 \%$ as assessed by autofluorescence. Isolation of primary hepatocytes was performed according to the method of (Guguen-Guillouzo and Guillouzo, 1986). Male Sprague-Dawley rats were used in all experiments.

\section{Experimental Models of Fibrosis}

$\mathrm{CCl}_{4}$-Induced Liver Fibrosis in Rats. Liver fibrosis was induced in Sprague-Dawley rats (180 gm; Charles River Laboratories, Margate, Kent, United Kingdom) by weekly intragastric administration of $\mathrm{CCl}_{4}$ for 15 weeks $(0.5 \mathrm{ml} / \mathrm{kg})$. Animals were killed 1 week after the final administration. Each liver was removed and cut into small pieces. Samples were immediately frozen for protein and RNA extractions. Others were fixed in formalin and embedded in paraffin for hematoxylin and eosin staining.

Bile Duct Ligation Protocol. DG expression was also studied in a mechanistically different model of liver fibrosis. Male Sprague-Dawley rats were either bile duct ligated or sham operated. In brief, under light anesthesia, the common bile duct was double ligated and sectioned between the ligatures. Sham-operated rats were treated in the same manner except that the bile duct was gently manipulated but not ligated or sectioned. All animals were killed 3 weeks after the surgical procedure. Liver fragments were fixed in formalin and embedded in paraffin for hematoxylin and eosin and Sirius Red staining, while other pieces were snap-frozen for RNA and protein extraction.

\section{Western Blot Analysis}

Proteins extracted from $\mathrm{HSC}$ or liver were subjected to SDS-PAGE under reducing conditions on $10 \%$ acrylamide gels and transferred to nitrocellulose filters by electroblotting. The blot was incubated for 1 hour in Tween-PBS with 5\% nonfat dry milk and incubated overnight at $4^{\circ} \mathrm{C}$ with any of the anti-DG antibodies (1:1000) diluted in Tween-PBS with 1\% nonfat dry milk. The blot was then washed 6 times ( 15 minutes each) with Tween-PBS and incubated with peroxidase-labeled secondary antibody for 1 hour at room temperature (Sigma). After washes with TweenPBS, the immunoreactive bands were detected using the ECL method.

\section{Real-Time RT-PCR}

mRNA were quantified by a real-time RT-PCR procedure (TaqMan). Quantitative real-time PCR was performed using the ABI PRISM 7700 Sequence Detection System (Perkin-Elmer Applied Biosystems, Foster City, California). The sequences of primers for $\mathrm{PO}$ (housekeeping genes encoding transcriptional factor) collagen $\alpha 1$ (I) and DG were designed using computer programs Oligo 4.0 (National Biosciences, Plymouth, Minnesota) and Primer Express (Perkin-Elmer Applied Biosystems).

Total RNA was extracted from frozen rat liver tissue or HSC by using the acid-phenol guanidinium method.
Reverse transcription of total RNA was performed in a final volume of $20 \mu$ containing $1 \times \mathrm{RT}$ buffer $(500 \mu \mathrm{M}$ each dNTP, $3 \mathrm{~mm} \mathrm{MgCl}$, $75 \mathrm{~mm} \mathrm{KCl,} 50 \mathrm{~mm}$ Tris- $\mathrm{HCl}$ $\mathrm{pH}$ 8.3), $10 \mathrm{U}$ of RNasin inhibitor (Promega, Madison, Wisconsin), $10 \mathrm{~mm}$ dithiothreitol, $50 \mathrm{U}$ of Superscript II RNase $\mathrm{H}^{-}$reverse transcriptase (Gibco BRL, Gaithersburg, Maryland), $1.5 \mu \mathrm{M}$ random hexamers (Pharmacia, Uppsala, Sweden), and $1 \mu \mathrm{g}$ of total RNA. Samples were incubated at $20^{\circ} \mathrm{C}$ for 10 minutes and $42^{\circ} \mathrm{C}$ for 30 minutes, and reverse transcriptase was inactivated by heating at $99^{\circ} \mathrm{C}$ for 5 minutes and cooling at $5^{\circ} \mathrm{C}$ for 5 minutes. Amplification reactions were set up in a reaction volume of $50 \mu$ l by use of components (except for primers and probes) supplied in a TaqMan PCR Core Reagent Kit (Perkin-Elmer Applied Biosystems) .

Ten microliters of diluted RT samples were used for quantitative two-step PCR (a 10-minute step at $95^{\circ} \mathrm{C}$, followed by 40 cycles of 15 seconds at $95^{\circ} \mathrm{C}$ and 1 minute at $65^{\circ} \mathrm{C}$ ) in the presence of $200 \mathrm{~nm}$ specific forward and reverse primers, $100 \mathrm{nM}$ specific fluorogenic probe, $5 \mathrm{~mm} \mathrm{MgCl}_{2}, 50 \mathrm{~mm} \mathrm{KCl,} 10 \mathrm{~mm}$ Tris buffer (pH 8.3), $200 \mu \mathrm{M}$ dATP, dCTP, dGTP and 400 $\mu \mathrm{M}$ dUTP, and 1.25 U of AmpliTaq Gold DNA polymerase (Perkin Elmer Applied Biosystems). Each sample was analyzed in duplicate, and a calibration curve constructed with a 10-fold serial dilution of total RNA extracted from immortalized HSC was run in parallel with each analysis. For each sample, the amount of DG was divided by the PO amount to obtain a normalized DG value.

\section{Cell Adhesion Assay}

After 7 days in culture, HSG in their fully activated phenotype were trypsinized and passaged. A total of 500,000 cells were added to $35-\mathrm{mm}$ laminin-coated dishes (Becton Dickinson) in the absence or presence of IIH6 at a 1:100 dilution, nonspecific mouse IgM (Sigma), IIH6 and $\mathrm{Ha} 2 / 5$ at a 1:100 dilution, $5 \mathrm{~mm}$ EDTA or $5 \mathrm{~mm}$ EDTA plus $10 \mathrm{~mm} \mathrm{CaCl}_{2}$. After 2 hours at $37^{\circ} \mathrm{C}$, shape and adhesion of the cells were observed. For quantification of cell adhesion, the amount of lactate dehydrogenase released in the medium was measured according to the lactate dehydrogenase assay kit (Sigma) as described previously (Legrand et al, 1992). Experiments were performed in duplicate. All LDH measures were compared with LDH measurement in medium of HSC incubated on laminin substrate without antibody or inhibitor and taken as reference.

\section{References}

Andac Z, Sasaki T, Mann K, Brancaccio A, Deutzmann R, and Timpl R (1999). Analysis of heparin, alpha-dystroglycan and sulfatide binding to the $\mathrm{G}$ domain of the laminin alpha1 chain by site-directed mutagenesis J Mol Biol 287:253-264.

Bioulac-Sage P, Lafon ME, Le Bail B, Boulard L, Dubuisson L, and Quinton A (1988). Ultrastructure of sinusoids in liver diseases. In: Bioulac-Sage P and Balabaud C, editors. Sinusoids in human liver: Health and disease. Rijswijk: The Kupffer Cell Foundation, 223-279. 
Bowe MA, Mendis DB, and Fallon JR (2000). The small leucine-rich repeat proteoglycan biglycan binds to alphadystroglycan and is upregulated in dystrophic muscle. J Cell Biol 148:801-810.

Campanelli JT, Roberds SL, Campbell KP, and Scheller RH (1994). A role for dystrophin-associated glycoproteins and utrophin in agrin-induced AchR clustering. Cell 77:663-674.

Carloni V, Romanelli RG, Pinzani M, Laffi G, and Gentilini P (1996). Expression and function of integrin receptors for collagen and laminin in cultured human hepatic stellate cells. Gastroenterology 110:1127-1136.

Clement B, Rissel M, Peyrol S, Mazurier Y, Grimaud JA, and Guillouzo A (1985). A procedure for light and electron microscopic intracellular immunolocalization of collagen and fibronectin in rat liver. J Histochem Cytochem 33:407-414.

Cohen MW, Jacobson C, Yurchenco PD, Morris GE, and Carbonetto $S$ (1997). Laminin-induced clustering of dystroglycan on embryonic muscle cells: Comparison with agrininduced clustering. J Cell Biol 136:1047-1058.

Colognato H, Winkelmann DA, and Yurchenco PD (1999). Laminin polymerization induces a receptor-cytoskeleton network. J Cell Biol 145:619-631.

Colognato $\mathrm{H}$ and Yurchenco PD (2000). Form and function: The laminin family of heterotrimers. Dev Dyn 218:213-234.

DiPersio CM, Hodivala-Dilke KM, Jaenisch R, Kreidberg JA, and Hynes RO (1997). alpha3beta1 Integrin is required for normal development of the epidermal basement membrane. J Cell Biol 137:729-742.

Durbeej M and Campbell KP (1999). Biochemical characterization of the epithelial dystroglycan complex. J Biol Chem 274:26609-26616.

Durbeej M, Henry MD, and Campbell KP (1998a). Dystroglycan in development and disease. Curr Opin Cell Biol 10:594601.

Durbeej M, Henry MD, Ferletta M, Campbell KP, and Ekblom P (1998b). Distribution of dystroglycan in normal adult mouse tissues. J Histochem Cytochem 46:449-457.

Eng FJ and Friedman SL (2000). Fibrogenesis I. New insights into hepatic stellate cell activation: The simple becomes complex. Am J Physiol Gastrointest Liver Physiol 279:G7G11.

Erickson AC and Couchman JR (2000). Still more complexity in mammalian basement membranes. J Histochem Cytochem 48:1291-1306.

Ervasti JM and Campbell KP (1993). A role for the dystrophinglycoprotein complex as a transmembrane linker between laminin and actin. J Cell Biol 122:809-823.

Friedman SL and Roll FJ (1987). Isolation and culture of hepatic lipocytes, Kupffer cells, and sinusoidal endothelial cells by density gradient centrifugation with Stractan. Anal Biochem 161:207-218.

Guguen-Guillouzo C and Guillouzo A (1986). Methods for preparation of adult and fetal hepatocytes: Isolated and cultured hepatocytes. Paris: John Libbey.

Hemler ME (1999). Dystroglycan versatility. Cell 97:543-546.

Henry MD and Campbell KP (1998). A role for dystroglycan in basement membrane assembly. Cell 11:95:859-870.

Henry MD and Campbell KP (1999). Dystroglycan inside and out. Curr Opin Cell Biol 11:602-607.
Hohenester E, Tisi D, Talts JF, and Timpl R (1999). The crystal structure of a laminin G-like module reveals the molecular basis of alpha-dystroglycan binding to laminins, perlecan, and agrin. Mol Cell 4:783-792.

Huang X, Poy F, Zhang R, Joachimiak A, Sudol M, and Eck MJ (2000). Structure of a WW domain containing fragment of dystrophin in complex with beta-dystroglycan. Nat Struct Biol 7:634-638.

Ibraghimov-Beskrovnaya O, Ervasti JM, Leveille CJ, Slaughter CA, Sernett SW, and Campbell KP (1992). Primary structure of dystrophin-associated glycoproteins linking dystrophin to the extracellular matrix. Nature 355:696-702.

Iwamoto $H$, Sakai $H$, and Nawata $H$ (1998). Inhibition of integrin signaling with Arg-Gly-Asp motifs in rat hepatic stellate cells. J Hepatol 29:752-759.

Legrand C, Bour JM, Jacob C, Capiaumont J, Martial A, and Marc A (1992). Lactate dehydrogenase (LDH) activity of the cultured eukaryotic cells as marker of the number of dead cells in the medium. J Biotechnol 25:231-243.

Levine D, Rockey DC, Milner TA, Breuss JM, Fallon JT, and Schnapp LM (2000). Expression of integrin alpha8beta1 during pulmonary and hepatic fibrosis. Am J Pathol 156: 1927-1935.

Lietard J, Loreal O, Theret N, Campion JP, L'Helgoualc'h A, and Turlin B (1998). Laminin isoforms in non-tumoral and tumoral human livers: Expression of alpha1, alpha2, beta1, beta2 and gamma1 chain mRNA and an alpha chain homologous to the alpha2. J Hepatol 28:691-699.

Moukhles H, Roque R, and Carbonetto S (2000). $\alpha$-Dystroglycan isoforms are differentially distributed in adult rat retina. J Comp Neurol 420:182-194.

Niki T, Pekny M, Hellemañs K, Bleser PD, Berg KV, Vaeyens F, and Quartier E (1999). Class VI intermediate filament protein nestin is induced during activation of rat hepatic stellate cells. Hepatology 29:520-527.

Raats CJ, van den Born J, Bakker MA, Oppers-Walgreen B, Pisa BJ, and Dijkman HB (2000). Expression of agrin, dystroglycan, and utrophin in normal renal tissue and in experimental glomerulopathies. Am J Pathol 156:1749-1765.

Rambukkana A, Yamada H, Zanazzi G, Mathus T, Salzer JL, and Yurchenco PD (1998). Role of alpha-dystroglycan as a Schwann cell receptor for Mycobacterium leprae. Science 282:2076-2079.

Russo K, Di Stasio E, Macchia G, Rosa G, Brancaccio A, and Petrucci TC (2000). Characterization of the betadystroglycan-growth factor receptor 2 (Grb2) interaction. Biochem Biophys Res Commun 274:93-98.

Saito F, Masaki T, Kamakura K, Anderson LV, Fujita S, and Fukuta-Ohi H (1999). Characterization of the transmembrane molecular architecture of the dystroglycan complex in Schwann cells. J Biol Chem 274:8240-8246.

Schaffner F and Popper H (1963). Capillarization of the sinusoids in man. Gastroenterology 44:239-242.

Shimizu $\mathrm{H}$, Hosokawa $\mathrm{H}$, Ninomiya $\mathrm{H}$, Miner $\mathrm{JH}$, and Masaki $\mathrm{T}$ (1999). Adhesion of cultured bovine aortic endothelial cells to laminin-1 mediated by dystroglycan. J Biol Chem 274: 11995-12000. 
Talts JF, Andac Z, Gohring W, Brancaccio A, and Timpl R (1999). Binding of the $G$ domains of laminin alpha1 and alpha2 chains and perlecan to heparin, sulfatides, alphadystroglycan and several extracellular matrix proteins. EMBO J 18:863-870.

Tisi D, Talts JF, Timpl R, and Hohenester E (2000). Structure of the C-terminal laminin G-like domain pair of the laminin alpha2 chain harbouring binding sites for alpha-dystroglycan and heparin. EMBO J 19:1432-1440.
Tunggal P, Smyth N, Paulsson M, and Ott MC (2000). Laminins: Structure and genetic regulation. Microsc Res Tech 51:214-227.

Yamada H, Denzer AJ, Hori H, Tanaka T, Anderson LV, and Fujita S (1996). Dystroglycan is a dual receptor for agrin and laminin-2 in Schwann cell membrane. J Biol Chem 271: 23418-23423.

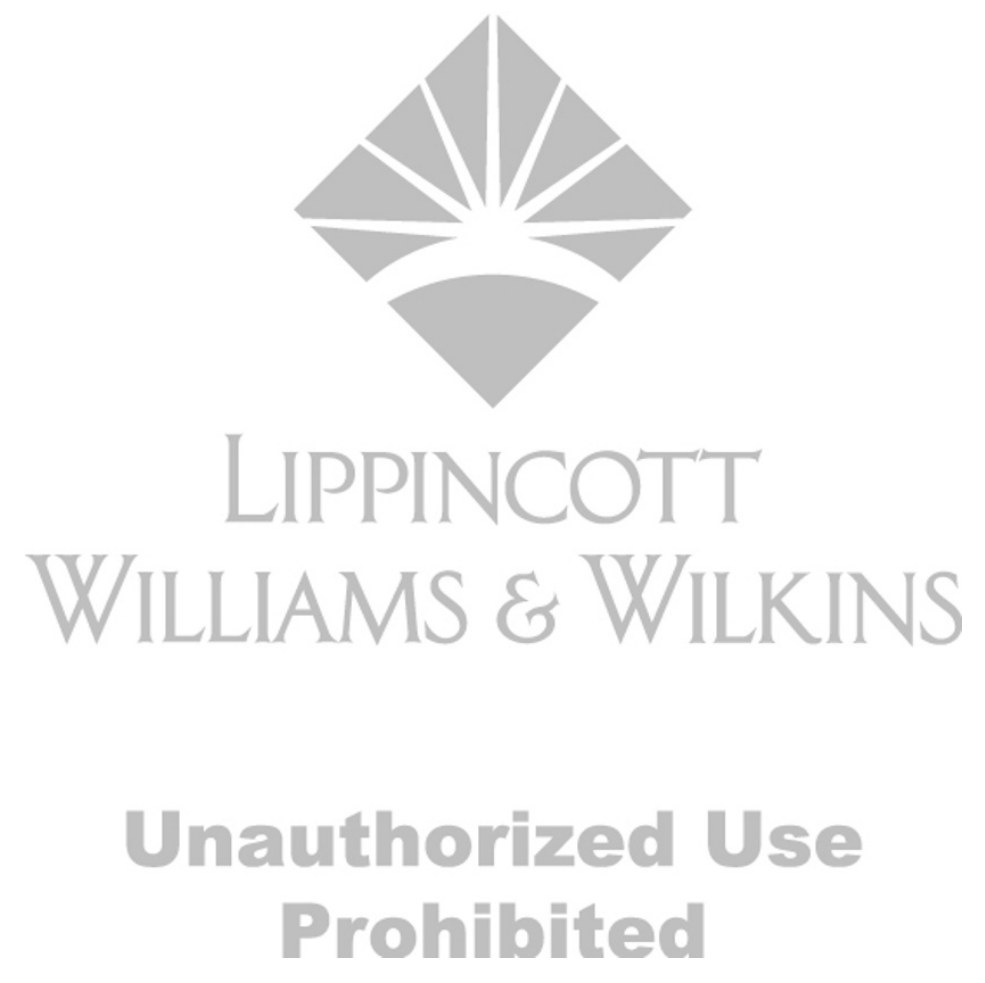

